\title{
Extracellular Biosynthesis of Silver Nanoparticles using Bacterial Isolate from Saline Soil
}

\author{
S.T. Pawar*, A. A. Bhosale, S.S. Gaikwad, J. Ayyadevra \\ Department of Microbiology, Tuljaram Chaturchand College of Arts, Science and Commerce, Baramati, Pune - 413 102, Maharashtra, India.
}

\section{AR T I C LE DET AILS}

\section{Article history:}

Received 28 October 2019

Accepted 27 November 2019

Available online 10 February 2020

\section{Keywords:}

Sliver Nanoparticles

Bacillus cereus

Antibacterial Efficiency

\begin{abstract}
A B S T R A C T
Nanotechnology is now known to be an area related to research and technology development. Nanoparticles have potential applications in the field of electronics, medicine and health. Nanotechnology is also proved in the medical field including therapeutics, drug discovery and diagnosis of diseases. An attempt has been made to isolate and identify the bacteria from saline soil and screening of all these bacteria for the synthesis of silver nanoparticles. Different bacterial cultures were isolated from saline soil samples from Baramati region. Isolated cultures were screened for extracellular biosynthesis of silver nanoparticles. The color change (white to brown) was observed after 72 hours of incubation. Among those bacteria the bacterial culture which showed absorption peaks in the range of 420-430 nm was selected for further characterization. Selected culture was identified using phenotypic and genotypic characteristics and was found to be Bacillus cereus. Characterization of nanoparticles was done using UV-visible spectral analysis, FTIR, SEM and XRD. The preparation showed characteristic absorption peak at $433 \mathrm{~nm}$. SEM analysis illustrated that the silver nanoparticles formed were fairly uniform in size with a hexagonal shape and an average diameter of $94 \mathrm{~nm}$. FTIR spectra revealed the presence of amino-methyl stretching groups and carbonyl groups. The antibacterial activity of the synthesized AgNPs was observed against human pathogens. The studies have indicated the potential of bacterial synthesized silver nanoparticles as bactericidal against human pathogens.
\end{abstract}

\section{Introduction}

One of the important features of nanotechnology is the synthesis of nanoparticles of different sizes, shape using new chemical, physical as well as biological methods. The chemical methods for the synthesis of nanoparticles may produce a large number of hazardous byproducts which is harmful to environment [1]. In last one-decade various metal oxides are used for synthesis of biological nanoparticles with number of biological applications [2]. These metal oxide nanoparticles are Silver nanoparticles, Alumina nanoparticles, Copper oxide nanoparticles, Gold nanoparticles, Iron nanoparticles, Magnesium oxide nanoparticles and Titanium dioxide nanoparticles [3-5]. A two-step mechanism for synthesis of silver nanoparticles using microbes is the first step involved trapping of $\mathrm{Ag}^{+}$ions at the surface of biological cells and in the second step enzymes silver nanoparticles [6-8]. Biosynthesis of nanoparticles is the major part of nanoscience and nanotechnology field. There are various nanoparticles are playing an important role in biomedical and various applications. Thus, there is a need for microbe mediated synthesis that includes a clean, nontoxic and ecofriendly method of nanoparticles synthesis [9]. Silver nanoparticles are synthesized by and that having very minute nanoparticles which are diverse application in the fields of health, medicine, agriculture and electronics etc. $[10,11]$. The nanoparticles showed the display of physical, chemical and biological properties and particles of controlled size with less than $100 \mathrm{~nm}[8,9]$. Silver ions and silver-based compounds are highly toxic to microorganisms showing strong inhibitory effect against harmful microorganisms. Therefore, silver nanoparticles inhibit the enzymes their transport to cell nutrient and weakening the cell membrane or cell wall needs to increase cell permeability and cell death [12]. Various microorganisms like bacteria, fungi, archeae and algae are synthesizing of metallic nanoparticles using the aqueous $\mathrm{Ag}^{+}$ions reduction [8,13-15]. Biosynthesized nanoparticles have biocidal activity against human pathogens as well as phytopathogens [16]. In the present study an attempt has been made to isolate and identify the bacteria from saline soil. The bacterial isolates were screened for the synthesis of silver nanoparticles extracellularly. Extracellular synthesized nanoparticles were characterized using UV-visible Spectral analysis, FTIR, SEM and XRD. The synthesized AgNPs were tested against human pathogens by disc diffusion antibacterial assay.

\section{Experimental Methods}

\subsection{Source of Microorganisms}

Soil samples were collected from the agricultural fields near Baramati as per standard protocol. These soil samples were analyzed for their physicochemical properties ( $\mathrm{pH}$ and Electrical conductivity). The soil samples which had $\mathrm{pH}$ above 8 and electrical conductivity above $4 \mathrm{ds} / \mathrm{m}$ were selected for this study. The bacteria were isolated from the above soil samples by serial dilution using spread plate method. The cultures were grown on nutrient agar plates and incubated at room temperature for 3 days. For purification purpose a single bacterial colony was selected and streaked on nutrient agar slants. The bacterial cultures were maintained at $4{ }^{\circ} \mathrm{C}$ in a refrigerator [17].

\subsection{Morphological and Biochemical Characterization of Isolates}

The colony characteristics like size, shape, color, elevation, margin, consistency, opacity, motility, gram staining, capsule staining and spore staining were recorded. Different biochemical tests were carried out like sugar utilization test, sugar fermentation test; catalase test, oxidase test starch hydrolysis test, nitrate reduction test and gelatin hydrolysis test. These colony characters and biochemical tests were used for identification of the isolates.

\subsection{Identification of Isolates}

Identification of the isolated organisms was done using their morphological characteristics and biochemical tests and compared with the key described in Bergey's Manual of Determinative Bacteriology $9^{\text {th }}$ edition. Molecular characterization of the isolate was also carried out Sequencing was done using Sanger's dideoxy methods performed on 3130 Genetic Analyzer (Applied Biosystem) at Vidya Pratishthan's School of Biotechnology, Baramati [17]. 


\subsection{Biosynthesis of Silver Nanoparticles from Bacterial Isolates}

Isolated cultures were inoculated in sterile $50 \mathrm{~mL}$ nutrient broth. The cultured flasks were incubated at room temperature for 72 hours on a rotary shaker (150 rpm). $20 \mathrm{~mL}$ cultures from each incubated flask were centrifuged at $10,000 \mathrm{rpm}$ for $10 \mathrm{~min}$ at room temperature. The biomass was discarded and cell free supernatant was used for the synthesis of the silver nanoparticles. 5\% cell free supernatant from each bacterial culture was added to the flasks containing silver nitrate at a concentration of 0.1 $\mathrm{g} / \mathrm{L}$. The reaction between these supernatants and silver ions were carried out for 72 hours [18].

\subsection{Characterization of Silver Nanoparticles}

\subsubsection{UV-Visible Spectrum Analysis}

The preliminary detection of silver nanoparticles was carried out by visual observation of color change (white to brown) of the culture filtrate. The reduction of silver ions was measured by using a UV-Visible spectrophotometer (Shimdzu UV-1800) at varying intervals ( $4 \mathrm{hrs}, 24 \mathrm{hrs,}$ $48 \mathrm{hrs}$ and $72 \mathrm{hrs}$ ) and scanning the spectra between $200-800 \mathrm{~nm}$ at the resolution of $1 \mathrm{~nm}$ [19]. The synthesized nanoparticles were separated using centrifugation at $10,000 \mathrm{rpm}$ for $10 \mathrm{~min}$ at room temperature and were used for further study.

\subsubsection{Scanning Electron Microscopy}

A scanning electron microscope was used to record the micrograph images of synthesized silver nanoparticles [20].

\subsubsection{Fourier Transform Infrared (FTIR) Analysis}

The silver nanoparticles were analyzed by Fourier transform infrared (FTIR) analysis. The dried silver nanoparticles were ground with $\mathrm{KBr}$ powder and passed into pellet for FTIR spectroscopy (Perkin Elmer Spectrum Version 10.03.06) between frequency range 450 to $4000 \mathrm{~cm}^{-1}$ with resolution $4 \mathrm{~cm}^{-1}$ [18].

\subsubsection{X-Ray Diffraction (XRD) Analysis}

The formation of silver nanoparticles was checked by X-ray diffraction (XRD) using an X-ray diffractometer. The supernatant treated with silver nitrate was evaporated to dryness under sunlight. The air-dried biomass was analyzed. The full widths at half maximum (FWHM) values of X-ray diffractions were used to calculate particles size [18].

\subsection{Determination of Antimicrobial Activity}

The silver nanoparticles synthesized from bacterial isolates were tested for antimicrobial activity by disc diffusion method against pathogenic microorganisms E. coli, Staphylococcus sp., Salmonella sp. and Pseudomonas sp. The pure culture of organisms was subcultured on nutrient agar slants and incubated at $37{ }^{\circ} \mathrm{C}$ for $24 \mathrm{hrs}$. Each strain was spread uniformly onto the nutrient agar plates. Discs were dipped into the samples of nanoparticles solution and placed onto the nutrient agar plates. After incubation at $37^{\circ} \mathrm{C}$ for $24 \mathrm{hrs}$, the zones of inhibition of bacteria were measured. The assays were performed in triplicate.

\section{Result and Discussion}

\subsection{Isolation and Characterization of Bacteria}

The isolated organisms were characterized for their morphological, microscopic observation (Fig. 1) and biochemical characteristics are given in Tables 1 and 2 respectively.

Table 1 Morphological characteristics

\begin{tabular}{llllll}
\hline Characteristics & Isolate 1 & Isolate 2 & Isolate 3 & Isolate 4 & Isolate 5 \\
\hline Size & $2 \mathrm{~mm}$ & $2 \mathrm{~mm}$ & $2 \mathrm{~mm}$ & $3 \mathrm{~mm}$ & $2 \mathrm{~mm}$ \\
Shape & Irregular & Circular & Circular & Circular & Circular \\
Color & White & Colorless & White & Greenish blue & Yellow \\
Elevation & Flat & Convex & Plain & Plain & Convex \\
Margin & Serrate & Entire & Entire & Regular & Entire \\
Opacity & Translucent & Opaque & Opaque & Transparent & Opaque \\
Consistency & Mucoid & Mucoid & Moist & Dry & Mucoid \\
Motility & Motile & Non motile & Motile & Non motile & Motile \\
Gram staining & Positive & Negative & Negative & Negative & Negative \\
& rods & rods & rods & rods & rods \\
Spore staining & Spore & Non spore & Non spore & Non spore & Non spore \\
& forming & forming & forming & forming & forming \\
Capsule & Capsulated & capsulated & Non & Non & Non \\
staining & & & capsulated & capsulated & capsulated
\end{tabular}

https://doi.org/10.30799/jnst.288.20060103

Cite this Article as: S.T. Pawar, A. A. Bhosale, S.S. Gaikwad, J. Ayyadevra, Extracellular biosynthesis of silver nanoparticles using bacterial isolate from saline soil, J. Nanosci. Tech. 6(1) (2020) 869-873.
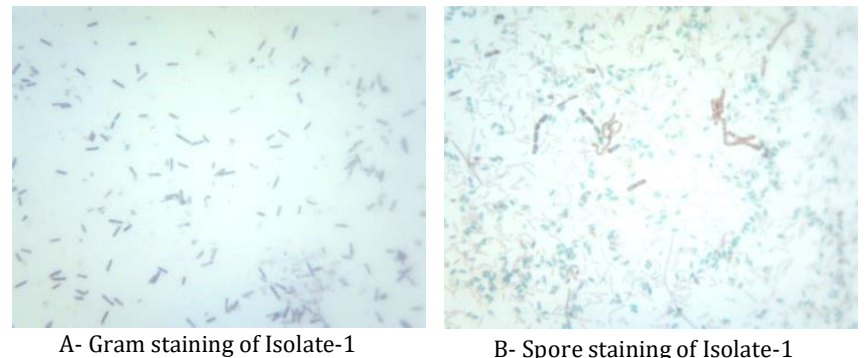

Fig. 1 Microscpic characterization of Isolate 1 (TCMB-1)

Table 2 Biochemical tests

\begin{tabular}{|c|c|c|c|c|c|}
\hline \multicolumn{6}{|c|}{ A- Sugar utilization and fermentation tests } \\
\hline Sugar & Isolate 1 & Isolate 2 & Isolate 3 & Isolate 4 & Isolate 5 \\
\hline Glucose & $+(\mathrm{A}, \mathrm{G})$ & $+(\mathrm{A}, \mathrm{G})$ & $+(\mathrm{A}, \mathrm{G})$ & $+(\mathrm{A}, \mathrm{G})$ & $+(\mathrm{A}, \mathrm{G})$ \\
\hline Maltose & $+(\mathrm{A}, \mathrm{G})$ & $+(\mathrm{A}, \mathrm{G})$ & $+(\mathrm{A}, \mathrm{G})$ & $+(\mathrm{A}, \mathrm{G})$ & $+(\mathrm{A}, \mathrm{G})$ \\
\hline Manitol & $+(A, G)$ & $+(\mathrm{A}, \mathrm{G})$ & $+(A, G)$ & $+(\mathrm{A}, \mathrm{G})$ & $+(\mathrm{A}, \mathrm{G})$ \\
\hline Fructose & - & $+(\mathrm{A}, \mathrm{G})$ & $+(\mathrm{A}, \mathrm{G})$ & $+(A, G)$ & $+(\mathrm{A}, \mathrm{G})$ \\
\hline Lactose & - & $+(\mathrm{A}, \mathrm{G})$ & $+(\mathrm{A}, \mathrm{G})$ & $+(A, G)$ & $+(\mathrm{A}, \mathrm{G})$ \\
\hline \multicolumn{6}{|c|}{ (+)- Positive test, (A)-Acid Production, (G)- Gas Production } \\
\hline \multicolumn{6}{|c|}{ B- Other Biochemical tests } \\
\hline Starch & + & - & + & - & + \\
\hline Gelatin & + & - & + & + & + \\
\hline Oxidase & - & - & - & + & + \\
\hline Catalase & + & + & + & + & + \\
\hline Nitrate reduction & + & + & + & + & + \\
\hline $\mathrm{H}_{2} \mathrm{~S}$ production & - & - & - & - & - \\
\hline
\end{tabular}

(+)- Positive test, (-) - Negative test

\subsection{Identification}

Identification was done on the basis of their morphological, microscopic, biochemical characteristics and using the key of Bergey's manual of determinative bacteriology ( $9^{\text {th }}$ edition). The identified genus name was shown in Table 3.

Table 3 Identification of Bacterial isolates

\begin{tabular}{lll}
\hline Isolates & Code & Name of organisms \\
\hline Isolate 1 & TCMB-1 & Bacillus $\mathrm{sp}$. \\
Isolate 2 & TCMB-2 & Klebsiella sp. \\
Isolate 3 & TCMB-3 & Azotobacter $\mathrm{sp}$. \\
Isolate 4 & TCMB-4 & Pseudomonas $\mathrm{sp}$. \\
Isolate 5 & TCMB-5 & Agrobacterium $\mathrm{sp}$. \\
\hline
\end{tabular}

These isolates were further used for the biosynthesis of silver nanoparticles. Molecular characterization of the isolate which showed the synthesis of silver nanoparticles was carried out. Sequencing was done in Vidya Pratishthan's, School of Biotechnology. Sequencing done using Sanger's dideoxy methods performed on 3130 Genetic Analyzer (Applied Biosystem). The cultures subjected to genomic DNA isolation and PCR amplification by Colony PCR; sequencing reaction by using Big Dye Terminator v3.1 sequencing kit. Sequences were assembled, edited and identified by using the sequence analysis tool- Blast and Clustal W. The phylogenetic tree generated using the neighboring joining method. The matrix used was Blosum 62. According to the phylogenetic tree, interested organism may belong to Bacillus sp. group and results were shown in Table 4 and Fig. 2.

Table 4 Molecular characterization of the isolate-1 (TCMB-1)

A-Sequence Analysis of given sample for Isolate-1 (TCMB-1)

Result:>1 Sequence (233 BP)

GTTGAGCTGTGGGCTTTCACATCGGACTTGGGAAACCACCTGCGCGCGCTTTACGCCCA ATAATTCCGGATAACGCTTGCCACCTACGTATTACCGCGGCTGCTGGCCCGTAGTTAGC CGCGGCTTTCTGGTTAGGTACCGTCAAGGTGCCAGCTTATTCAACTAGCACTTGTTCT TCCCTAACAACAGAGTTTTACGACCCGAAAGCCTTCATCACTCACGCGGCGTTGCTC

\begin{tabular}{|c|c|c|c|c|}
\hline $\begin{array}{l}\text { Select seq } \\
\text { gb|HM196279.1| }\end{array}$ & $\begin{array}{l}\text { Bacillus sp. BC6 16S } \\
\text { |ribosomal RNA gene, } \\
\text { partial sequence }\end{array}$ & 409409 & $100 \% 8 \mathrm{e}-11198 \%$ & HM196279.1 \\
\hline $\begin{array}{l}2 \text { Select seq } \\
\text { gb|KF917857.1| }\end{array}$ & $\begin{array}{l}\text { Uncultured bacterium } \\
\text { clone A1-84 16S } \\
\text { ribosomal RNA gene, } \\
\text { partial sequence }\end{array}$ & 403403 & $100 \% 4 \mathrm{e}-10998 \%$ & KF917857.1 \\
\hline $\begin{array}{l}3 \text { Select seq } \\
\text { gb|KF649250.1| }\end{array}$ & $\begin{array}{l}\text { Bacillus cereus strain } \\
\text { Lgb-21 16S ribosomal } \\
\text { RNA gene, partial } \\
\text { sequence }\end{array}$ & 403403 & $100 \% 4 \mathrm{e}-10998 \%$ & KF649250.1 \\
\hline
\end{tabular}




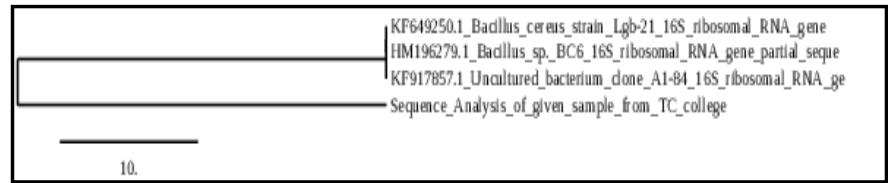

Fig. 2 Phylogenetic Tree: 98\% Matching of Isolate-1 sequence to above mentioned other sequences

\subsection{Biosynthesis of Silver Nanoparticles}

In the present study, extracellular biosynthesis of silver nanoparticles by the culture supernatant of isolates was studied. Visual observations showed a change of color in silver nitrate solution from white to brown (Fig. 3). Whereas no color change was observed in the culture supernatant without silver nitrate or in media with silver nitrate alone.

The appearance of a brown color in silver nitrate treated cultures supernatant suggested the formation of silver nanoparticles. A similar observation was made by Duran [21]; in the biosynthesis of Ag-NPs by Fusarium oxysporum strain and by Jeevan [18]; in the biosynthesis of AgNPs by Pseudomonas aeruginosa strain by extracellular process. The brown color of the medium could be due to the excitation of surface Plasmon vibration of silver nanoparticles [22].

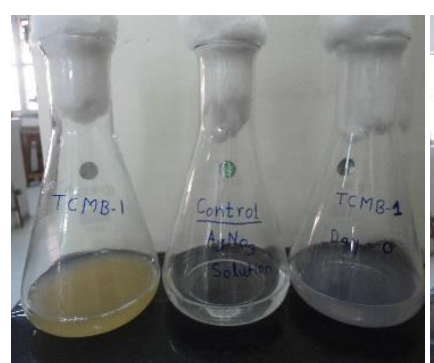

A- 0 Hr (beginning)

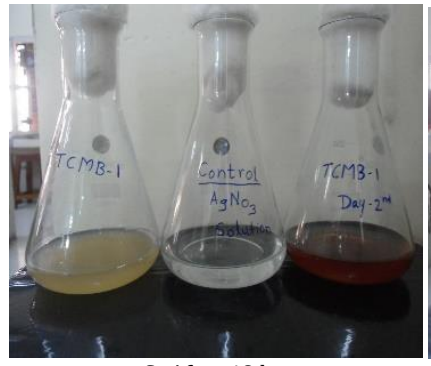

C- After 48 hrs

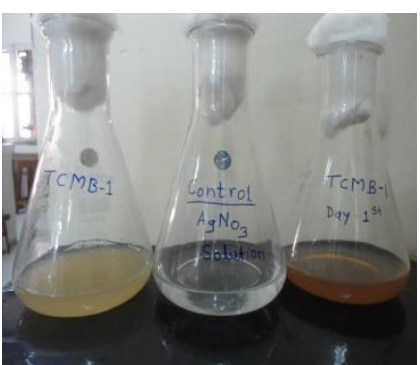

B- After 24 hrs

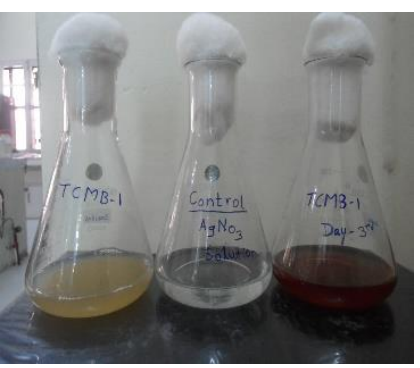

D- After $72 \mathrm{hrs}$
Fig. 3 Biosynthesis of silver nanoparticles

The exact mechanism of biosynthesis of Ag-NPs is not known. However, it has been hypothesized that silver ions required the NADPH-dependent nitrate reductase enzyme for their reduction, which was secreted by the bacteria in its extracellular environment $[18,23]$. The use of these enzymes has previously been demonstrated in the in vitro synthesis of silver nanoparticles under anaerobic condition. Nitrate reductase is known to shuttle electron from nitrate to the metal group. Thus, these results substantiate the role of nitrate reductase enzymes in the biosynthesis of silver nanoparticles [24].

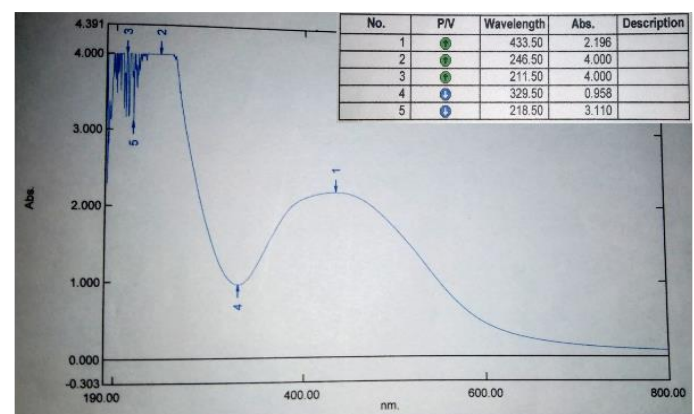

Fig. 4 UV-Visible spectrum analysis of biosynthesized nanoparticles by Isolate-1 (Bacillus sp.)

\subsection{Characterization of Silver Nanoparticles}

\subsubsection{UV-Visible Spectrum Analysis}

The synthesized Ag-NPs were characterized by UV-Vis spectroscopy. In the UV-Vis absorption spectrum of isolate 1 synthesized silver https://doi.org/10.30799/jnst.288.20060103 nanoparticle showed a strong, broad peak located at $433 \mathrm{~nm}$. Observation of this peak, assigned to a surface Plasmon, is well documented for various metals nanoparticles with sizes ranging from 2-100 $\mathrm{nm}[18,25,8]$.

\subsubsection{Scanning Electron Microscopy}

Fig. 5 shows a representative SEM image recorded form the drop coated film of the silver nanoparticles synthesized in the present study. The particle size ranges from 43-159 $\mathrm{nm}$ and possesses an average size of 94 $\mathrm{nm}$. Whereas Jeevan [18] observed the silver nanoparticles size ranges from 20-100 $\mathrm{nm}$ and average size was $50 \mathrm{~nm}$. Sudha [26] reported the synthesis of polydisperse spherical silver nanoparticles using microalgae in the range 44-79 $\mathrm{nm}$ with average size of $55 \mathrm{~nm}$. The results obtained from the SEM image gave the clear shape and size of the silver nanoparticles produced from the isolate 1 . The diameter of the silver nanoparticles in the solution was found to be in the range of $43-159 \mathrm{~nm}$.
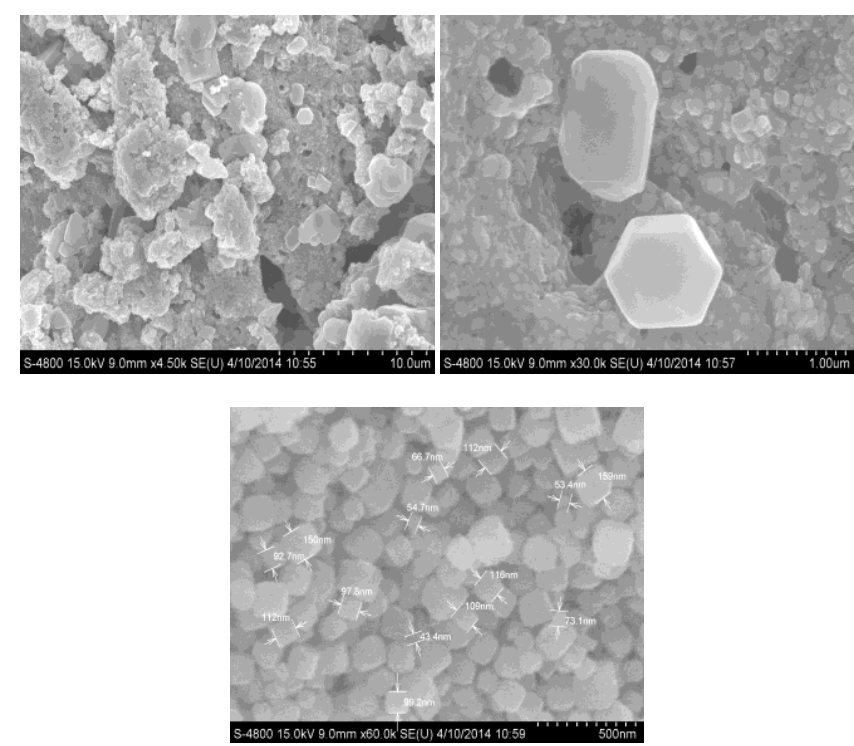

Fig. 5 SEM micrograph of silver nanoparticles formed after reaction of culture supernatant with silver nitrate solution

\subsubsection{Fourier Transform Infrared (FTIR) Analysis}

FTIR measurement were carried out to identify possible interaction between silver salts and protein molecules, which could account for the reduction of silver ions and stabilization of silver nanoparticles formed after 72 hrs (Fig. 6). The amide linkages between amino acid residues in protein give rise to the well know signature in the infrared region of the electromagnetic spectrum. The bands seen at $3058.63 \mathrm{~cm}^{-1}, 2918.57 \mathrm{~cm}^{-1}$ and $2876.5 \mathrm{~cm}^{-1}$ were assigned to the aromatic, $\mathrm{C}-\mathrm{H}\left(-\mathrm{CH}_{2-}^{-},-\mathrm{CH}_{3}\right)$, and Alkyl groups, respectively.

The bands seen at $1788.37 \mathrm{~cm}^{-1}, 1594.98 \mathrm{~cm}^{-1}$ and $1549.77 \mathrm{~cm}^{-1}$ corresponds to carbonyl and phenyl groups, while the band at $1383.84 \mathrm{~cm}^{-}$ 1 is characteristic of amine and amino-methyl stretching groups. The bands seen at $1651.27 \mathrm{~cm}^{-1}$ is characteristic of $-\mathrm{C}=0$ carbonyl group and $-\mathrm{C}=\mathrm{C}$ stretching. Jeevan et al. reported that $1639.16 \mathrm{~cm}^{-1}$ showed characteristics of carbonyl groups. The bands seen at $788.53 \mathrm{~cm}^{-1}, 723.54 \mathrm{~cm}^{-1}$ and 664.83 $\mathrm{cm}^{-1}$ is characteristic of $\mathrm{R}-\mathrm{NH}_{2}$ (Broad), $\mathrm{CH}=\mathrm{CH}$ (isomers) and alcohol (neat) groups.

The overall observation confirms the presence of protein in samples of silver nanoparticles. It has also been reported earlier that protein can bind to nanoparticles either through their free amine group or cysteine residues [27]. Therefore, stabilization of silver nanoparticles by protein is a clear possibility.

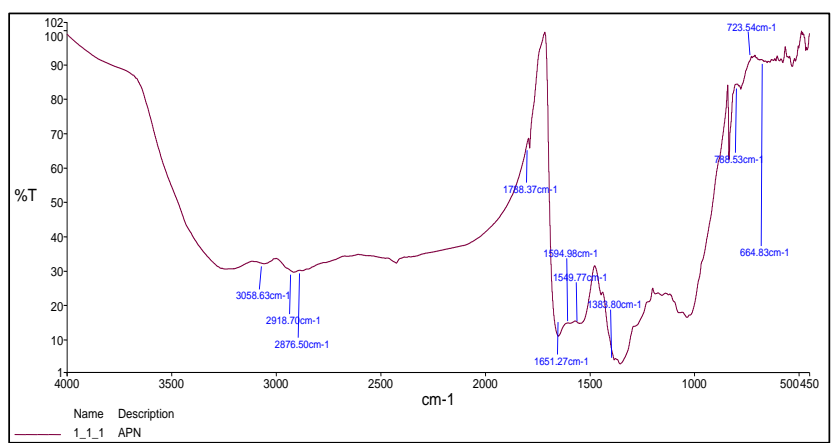

Fig. 6 FTIR spectra recorded from powder of biosynthesized silver nanoparticles 


\subsubsection{X-Ray Diffraction (XRD) Analysis}

$\mathrm{X}$-ray diffraction (XRD) was carried out to confirm the crystalline nature of the particles and the XRD pattern obtained is shown in Fig. 7. The XRD pattern showed four intense peaks in the whole spectrum of $2 \varnothing$ values ranging from 20-80. A comparison of the XRD spectrum with the standard confirmed that the silver particles formed in the particle study were in the form of nano-crystals as evident form of nano-crystals as evident from the peaks at $2 \emptyset$ values of $26.923,31.337,37.206,45.345,53.939,56.599$, $63.555,66.570,73.635$ and 75.892 corresponding to (570), (1168), (68.1), (615), (145), (143), (33.9), (54.4), (22.1) and (123) respectively for silver. XRD analysis of silver nanoparticles synthesized by Spirulina platensis [19] and Pseudomonas aeruginosa [18] showed intense peaks, corresponding to (111), (200) and (220) Bragg reflection, based on the face-centered cubic (fcc) structure of silver nanoparticles.

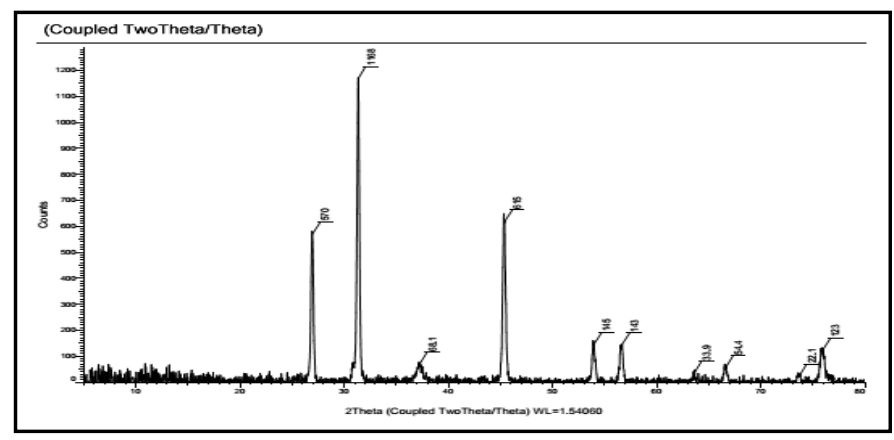

Fig. 7 representative XRD pattern of silver nanoparticles formed after reaction of culture supernatant with silver nitrate solution

\subsection{Antimicrobial Activity of Synthesized Silver Nanoparticles}

The antimicrobial activity of silver nanoparticles was observed against pathogens, viz., E. coli, Staphylococcus sp., Salmonella sp. and Pseudomonas sp. using disc diffusion method. The antimicrobial activity of silver nanoparticles produced by isolate 1 obtained from the present study is shown in Table 5 and Fig. 8.

Table 5 Antibacterial activity of biosynthesized silver nanoparticles

\begin{tabular}{lll}
\hline Test bacteria & Zone of inhibition $(\mathrm{mm})$ \\
\cline { 2 - 3 } & Standard antibiotics & Biosynthesized AgNPs \\
\hline E. coli & 17 (Cephalosporin) & 12 \\
Staphylococcus sp. & 15 (Amphicillin) & 11 \\
Salmonella sp. & 14 (Azithromycin) & 09 \\
Pseudomonas sp. & 15 (Tobramycin) & 11 \\
\hline
\end{tabular}

The results showed maximum antibacterial effects against $E$. coli $(12$ $\mathrm{mm})$, Staphylococcus sp. (11 mm), Pseudomonas sp. $(11 \mathrm{~mm})$ and minor antibacterial effect was recorded against Salmonella sp. $(9 \mathrm{~mm})$. Deljou and Goudarzi [1] reported the silver nanoparticles showed the highest activity against the $E$. coli with $22 \mathrm{~mm}$ of zone of growth inhibition while other pathogens were also affected by AgNPs but shown the lower range of inhibition. Cyanobacterium Oscillatoria sp. showed the effective inhibitory action of synthesized silver nanoparticles against different human pathogen like E. coli, Staphylococcus sp., Salmonella sp. and Pseudomonas sp. using disc diffusion method [8].

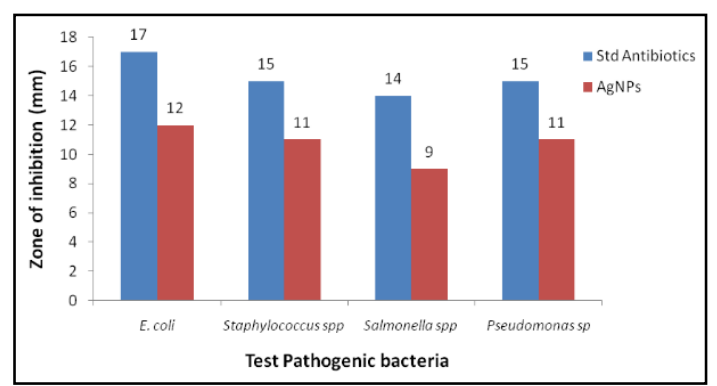

Fig. 8 Graphical representation of antimicrobial effect of silver nanoparticles with bacterial and standard antibiotics

\section{Conclusion}

It is concluded that among the five isolates of bacteria, Bacillus sp. (Isolate 1) synthesized silver nanoparticles. In the analysis by UV-Vis spectrum and SEM the biosynthesis of silver nanoparticles and its size was determined. Also, XRD and FTIR analysis confirmed the shape of synthesized nanoparticles and presence of protein. The bioactivity of the synthesized silver nanoparticles had inhibitory effect on important human pathogens. Thus, the bacterium Bacillus sp. can be used to synthesize bioactive nanoparticles efficiently.

\section{Acknowledgement}

Authors are thankful to the Principal, Tuljaram Chaturchand College, Baramati for providing necessary facilities and constant help during the research period and also to Head, Department of Microbiology and Faculty members, Department of Microbiology, T.C.College, Baramati.

Authors are thankful to the Director, Vidya Pratishthan's School of Biotechnology, Baramati for providing necessary facilities and constant help during the research period.

\section{References}

[1] A. Deljou, S. Goudarzi, Green Extracellular synthesis of the silver nanoparticles using Thermophilic Bacillus Sp. AZ1 and its antimicrobial activity against several human pathogenetic bacteria, Iran J. Biotech. 14(2) (2016) 25-32.

[2] G. Chandraprabha, T. Sankarappa, B.J. Lokhande, T. Sujatha, Studies on conduction mechanism, magnetization and electrochemical properties of polythiophene-cobalt nanocomposites, J. Nanosci. Tech. 4(1) (2018) 304-307.

[3] V.L. Das, R. Thomas, R.T. Varghese, E.V. Soniya, J. Mathew, E.K. Radhakrishnan Extracellular synthesis of silver nanoparticles by the Bacillus strain CS 11 isolated from industrialized area, Biotech 4 (2014) 121-126.

[4] A.S. Vidyarthi, S. Tikariha, S. Singh, S. Banerjee, Biosynthesis of gold nanoparticles, scope and application: A review, Int. J. Pharm. Sci. Res. 3 (2012) 1603-1615.

[5] G. Annadurai, C. Malarkodi, S. Rajeshkumar, K. Paulkumar, G. Gnanajobitha, M. Vanaja, Bacterial synthesis of silver nanoparticles by using optimized biomass growth of Bacillus sp, Nanosci. Nanotech. Int. J. 3 (2013) 26-32.

[6] P. Khandel, S.K. Shahi, Microbes mediated synthesis of metal nanoparticles: current status and future prospects, Int. J. Nanomat. Biostruct. 6 (2016) 1-24.

[7] R. Kumar, A. Ahmad, S. Senapati, M.I. Khan, M. Sastry, Extracellular biosynthesis of monodisperse gold nanoparticles by a novel extremophilic actinomycete, Thermomonospora sp, Langmuir 19(8) (2003) 3550-3553.

[8] S. Pawar, A. Bhosale, P. Mulani, P. Patekar, S. Shaha, Screening of silver nanoparticles producing cyanobacteria and its characterization, Int. Res. J. Sci. Eng. A1 (2017) 44-54.

[9] N. Thajuddin, D.M. Ali, M. Sasikala, M. Gunashekharan, Biosynthesis and characterization of silver nanoparticles using marine cyanobacterium, Oscillatoria willei NTDM 01, Dig. J. Nanomat. Biostruct. 6 (2011) 385-390.

[10] F.A. Al-Dhabaan, T. Shoala, A.A.M. Ali, M. Alaa, K. Abd-Elsalam, Chemicallyproduced copper, zinc nanoparticles and chitosan-bimetallic nanocomposites and their antifungal activity against three phytopathogenic fungi, Int. J. Agri. Technol. 13(5) (2017) 753-769.

[11] A. Khandelwal, R. Joshi, Synthesis of nanoparticles and their application in agriculture, Acta Sci. Agri. 2(3) (2018) 10-13.

[12] K. Sahayaraj, S. Rajesh, Bionanoparticles, synthesis and antimicrobial applications, In Book: Science against microbial pathogens; communicating current research and technological advances, Formatex Research Center Spain, 2011, pp.228-244.

[13] J. Jena, N. Pradhan, B.P. Dash, L.B. Shukla, P.K. Panda, Biosynthesis and characterization of silver nanoparticles using microalga Chlorococcum humicola and its antibacterial activity, Int. J. Nanomat. Biostruct. 3 (2013) 1-8.

[14] V. Patel, D. Berthold, P. Puranik, M. Gantar, Screening of cyanobacteria and microalgae for their ability to synthesize silver nanoparticles with antibacterial activity, Biotech. Rep. 5 (2015) 112-119.

[15] A.S. Sherkhane, H.H. Suryawanshi, P.S. Mundada, B.P. Shinde, Silver nanoparticles: The powerful antidote for bacterial blight disease of pomegranate, J. Nanosci. Tech. 4(4) (2018) 421-423.

[16] A.S. Sherkhane, H.H. Suryawanshi, A.A. Daspute, A.A. Bhosale, R.J. Sharma, B.P. Shinde, Silver nanoparticles: The powerful antidote for disease in pomegranate, J. Nanosci. Tech. 5(1) (2019) 613-615.

[17] S.T. Pawar, A.A. Bhosale, T.B. Gawade, T.R. Nale, Isolation, screening and optimization of exopolysaccharide producing bacterium from saline soil, J. Microbiol. Biotech. Res. 3(3) (2013) 24-31.

[18] P. Jeevan, K. Ramya, A.E. Rena, Extracellular Biosynthesis of silver nanoparticles by culture supernatant of Pseudomonas aeruginosa, Ind. J. Biotech. 11 (2012) 72-76.

[19] M. Mahdieh, A. Zolanvari, A.S. Azimee, Green biosynthesis of silver nanoparticles by Spirulina platensis, Scientia Iranica F. 3 (2012) 926-929.

[20] K. Lingappa, D. Biradar, Isolation and screening of gold nanoparticles by microbes, World J. Sci. Tech. 2 (2012) 20-22.

[21] N. Duran, G.I.H. De Souza, O.L. Alves, E. Esposito, P.D. Marcatu, Antimicrobia activity of silver nanoparticles synthesized by Fusarium oxysporum strain, J Nanotech. (2003) 122-128.

[22] Z. Ahmad, R. Pandey, S. Sharma, G.K. Khuller, Alginate nanoparticles as antituberculosis drug carriers: formulation development, pharmacokinetics and therapeutic potential, Indian J. Chest. Dis. Alld. Sci. 48 (2005) 171-176.

[23] K. Kalishwaralal, V. Deepak, S. Ramkumarpandian, H. Nellaiah, G. Sangiliyandi, Extracellular biosynthesis of silver nanoparticles by the culture supernatant of Bacillus licheniformis, Mater Lett. 62 (2008) 4411-4413. 
[24] M. Gajbhiye, J. Kesharwani, A. Ingle, A. Gade, M. Rai, Fungus mediated synthesis of silver nanoparticles and their activity against pathogenic fungi in combination with fluconazole, Nanomed. 5 (2009) 382-386.

[25] P. Tillmann, Stability of silver nanoparticles in aqueous and organic media, J. Mater. Chem. 4 (2004) 140-146.
[26] S.S. Sudha, K. Rajamanickam, J. Ringaramanujan, Microalgae mediated synthesis of silver nanoparticles and their antibacterial activity against pathogenic bacteria, Ind. J. Exp. Biol. 52 (2013) 393-399.

[27] A. Gole, C. Dash, V. Ramachandran, S. Sainkar, A. Mandale, et al, Pepsin-gold colloid conjugates: preparation, characterization, and enzymatic activity, Langmuir. 17 (2001) 1674-1679. 